\title{
Noninvasive Technique for Acquiring and Analysis of Electrogastrogram
}

\author{
G.Gopu \\ Department of EEE \\ PSG College of Technology \\ Coimbatore-04, \\ Tamilnadu, India
}

\author{
R.Neelaveni \\ Department of EEE \\ PSG College of Technology \\ Coimbatore-04, \\ Tamilnadu, India
}

\author{
K.Porkumaran \\ Department of BME \\ Sri Ramakrishna Engineering College \\ Coimbatore-22, \\ Tamilnadu, India.
}

\begin{abstract}
In this paper, we proposed an engineering approach as a noninvasive technique for acquiring and analysis of Electrogastrogram [EGG]. Active electrode [AE] setup is used to acquire the myoelectrical activity of the stomach due to its higher sensitivity of a acquiring the Electrogastrogram [EGG] signals compare to passive electrode and it is most reliable because signal loss is prevented. By using appropriate filter and by using Electromagnetic Interference [EMI] shield. EGG recorded for more than hundred and fifty human being includes the normal individual and patients with digestive system disorder such us Bradygastria, Tachygastria, Dyspepsia, etc. A database is created for the analysis purpose. The change in frequency and Power for disorders patients compare to normal Individual from the power spectrum plot. Wavelet Transform analysis includes Discrete Wavelet Transform [DWT] to analyze the signal for the diagnosis of various gastric disorders as mentioned above. In wavelet analysis, the data of a patient or normal individual is considered. The signal is reconstructed with a data obtained through data scope. This input signal undergoes Principle Component Analysis [PCA] as a preprocessing and then the interference and noise in the EGG signal are removed to obtain de-noised signal. The denoised EGG signal is plotted for power spectral density estimation with Welch power spectral Density Estimation. As a result of the proposed method the signal is analyzed up to five levels. The DWT is applied using the $\mathrm{db} 4$. The wavedec, appcoef and wrcoef commands in the MATLAB are used to apply the transform and plot the coefficients. From the reconstructed signal plot it is found those 5 peaks $(3 \mathrm{cpm})$ for normal subject, large number of peaks for Tachygastria and less number of peaks for Bradygastria.
\end{abstract}

\section{Keywords}

Electrogastrogram, Active Electrode, Tachygastria, Bradygastria, DWT

\section{INTRODUCTION}

Gastric Electrical Activity [GEA] due to the stomach motility is measured cutaneously using the surface electrodes $(\mathrm{Ag} / \mathrm{Agcl})$ is called Electrogastrography [1, 2].EGG includes the fundamental frequency such us electrical control activity of the stomach (ECA) of the stomach and the electrical response activity (ERA).Before 75years W.C Alvarez is published about the EGG but the first recording of gastro electrical activity is performed in dogs by C.F. Code and J.A.Marleh in the year 1974 [3] and in human this procedure is recorded in 1978 [4] by R.L.Telander et al. However, the progress in this field has been very slow because of its difficulty in data acquisition, lack of understanding, etc. Due to the advancement in quantitative analysis of the EGG, more and more physicians and biomedical researchers interested in this field. The abnormality arises due to Dyspepsia, Stomach ulcer, Tachygastria, Bradygastria, etc., which results in improper digestion of food by the stomach. If the EGG is abnormal, it confirms that the problem probably is with the stomach's muscles or the nerves that control the muscles. This paper mainly deals with the denoising of EGG using wavelets Daubechies wavelet Transform. The denoising of the EGG by db4 wavelet is found good compare to Haar and other wavelets. The EGG of preprandial and postprandial for a subjects with Bradygastria and with Tachygastria is obtained by the Discrete Wavelet Transform [CWT].The denoised EGG signal's frequency and power in $\mathrm{db}$ is obtained with Welch power spectral Density Estimation. More than 150 subjects were studied for the investigation of the digestive system disorders as mentioned above.

\section{ABOUT ELECTROGASTROGRAM}

An EGG is similar to an electrocardiogram of the heart. It is a recording of the electrical signals that travel through the muscles of the stomach and control the muscle's contraction $[14,15,16]$. EGG used when there is a suspicion that the muscles of the stomach or the nerves controlling the muscles are not working normally. EGG done by placing the electrode cutaneously over the stomach and the electrical signals coming from the stomach's muscles are sensed by the electrode and recorded on a computer for analysis by lying patient quietly. In normal individuals the EGG is a regular electrical rhythm generated by the muscles of the stomach and the power (voltage) of the electrical current increases after the meal. In patients with abnormalities of the muscles or nerves of the stomach, the rhythm often is irregular or there is no post-meal increase in electric power. EGG will not have any side effects and it is painless study.

\section{RECORDING SETUP WITH ACTIVE ELECTRODE}

In this proposed recoding setup the active electrodes are used to acquire the electrical signals directly from the stomach, which are used to buffer the signals and also provide impedance matching. The active electrodes are well protected within a shield to reduce electromagnetic interference. EGG from active electrode is undergoes for signal conditioning in SCU unit, which include instrumentation amplifier (IA) and filter. IA is high input 
impedance and high CMRR about $100 \mathrm{db}$ with variable gain 1 to 10000. The noise due to respiratory, cardiac and other bio signals along with motion artifacts is also acquired with EGG. This is eliminated in the filter section and the frequency range from 1 to $10 \mathrm{cpm}$ of EGG is viewed in the digital storage scope (DSO).The EGG given to data scope to convert the analog form into digital form to store as database in the PC via RS 232 serial interface for analysis and classification to assist the physician in the investigation of digestive system disorder. The general block

Stomach

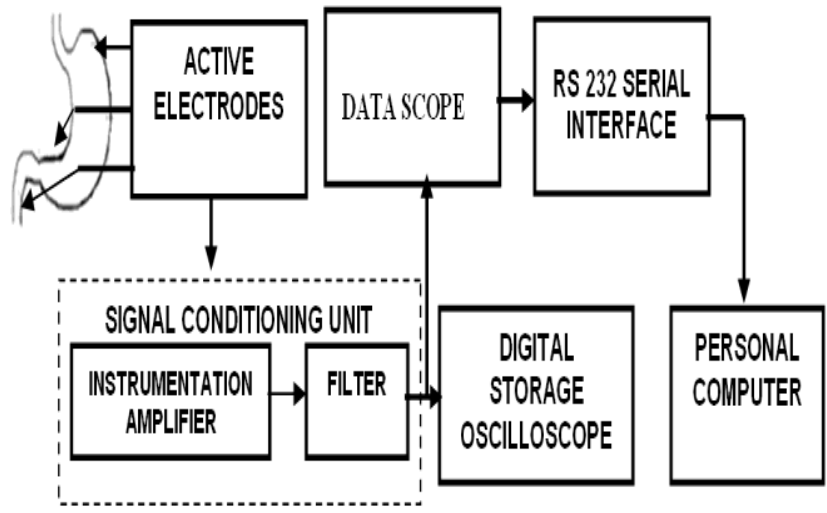

diagram for the above said proposed recoding setup is shown in Figure 1.

Figure 1. General Block Diagram

\section{ACTIVE ELECTRODE POSITION}

The electrical signals are generally produced in the mid-corpus of the stomach where the electrical activity takes place.

A

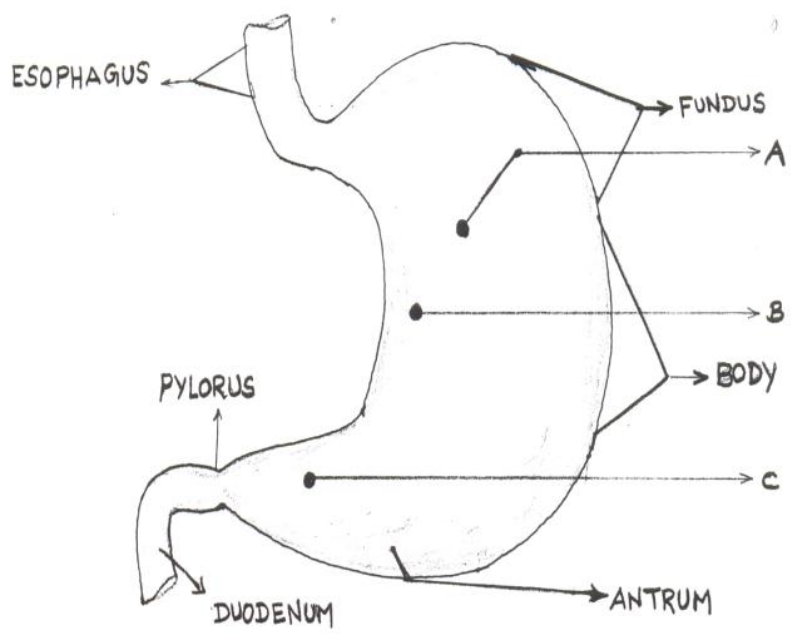

The positioning of the Active electrodes for tapping of these signals is as follows as shown Figure 2 (A) and Figure 2 (B) shows the real time acquisition with $\mathrm{AE}$. Two electrodes $\mathrm{A}$ and $\mathrm{B}$ are placed in the fundus and the mid corpus of the stomach. The third electrode $\mathrm{C}$ is placed as ground at the end of the stomach region for patient safety $[5,6,7]$.

B

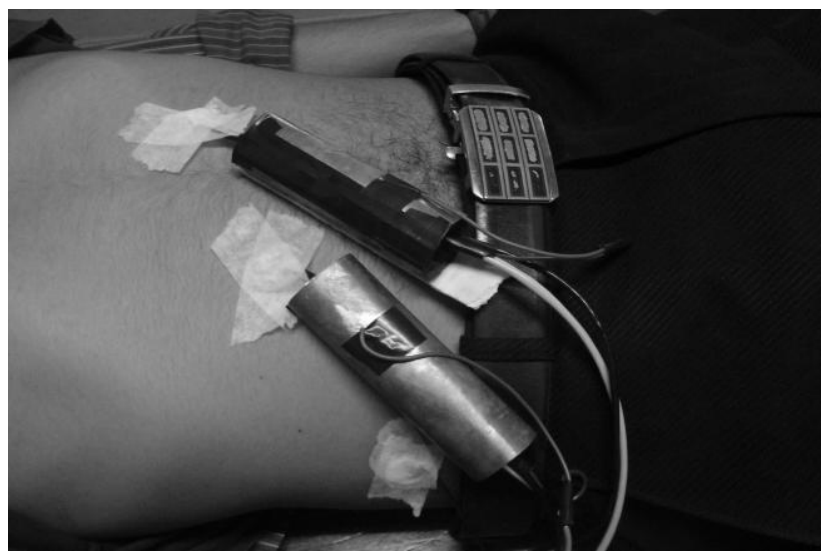

Figure 2. Active Electrodes Positioning for Recording EGG

\section{MATERIALS AND METHODS}

The outpatient's gastroenterology clinic and the student with disorders were studied for this investigation at biomedical department of our institution and gastroenterology department of a reputed hospital. More than hundred numbers, includes patients, normal subjects in both male and female category of different age groups are participated in this recording [8, 10]. The patients included 40 with Dyspepsia, 45 with Stomach ulcer, and 25 with Nausea, 25 with Bradygastria and 20 with tachygastria are included for this analysis. This acquisition of data started before four years and till date to for strong database. The various categories of the subjects are listed in Table 1.

Table 1. Sex and Age distribution of patients group

\begin{tabular}{|c|c|c|c|}
\hline Disorders & $\begin{array}{c}\text { Mean Age } \\
\text { (years) }\end{array}$ & Male & Female \\
\hline $\begin{array}{c}\text { Dyspepsia } \\
(\mathrm{n}=40)\end{array}$ & 38 & 24 & 16 \\
\hline $\begin{array}{c}\text { Stomach Ulcer } \\
(\mathrm{n}=45)\end{array}$ & 34 & 26 & 19 \\
\hline $\begin{array}{c}\text { Nausea } \\
(\mathrm{n}=25)\end{array}$ & 28 & 15 & 20 \\
\hline $\begin{array}{c}\text { Bradygastria } \\
(\mathrm{n}=25)\end{array}$ & 36 & 12 & 08 \\
\hline $\begin{array}{c}\text { Tachygastria } \\
(\mathrm{n}=20)\end{array}$ & & \\
\hline
\end{tabular}

The electrodes are positioned as described in the section 4 of this paper to record the data after lightly abrade the skin with abrasive pads and the gel is applied to the electrode contact area. The output of the electrode is given to the instrumentation amplifier of the recording setup. The amplified signal undergoes preprocessing and then the data are acquired via data scope and the same is stored as database in the computer for further 
analysis. In this paper, EGG data are reconstructed as an original EGG signal and the same is included in the PCA as a preprocessing step to get actual EGG signal. Denoising of the half an hour recorded EGG signal is performed with wavelet denoising technique to find the frequency and power spectrum. The Figure 3 represents the denoising of an EGG signal with Haar wavelet and the Figure 4 represents the denoising of an EGG signal with db4 wavelet. As a finding, the denoising by db4 is better than Haar wavelet.
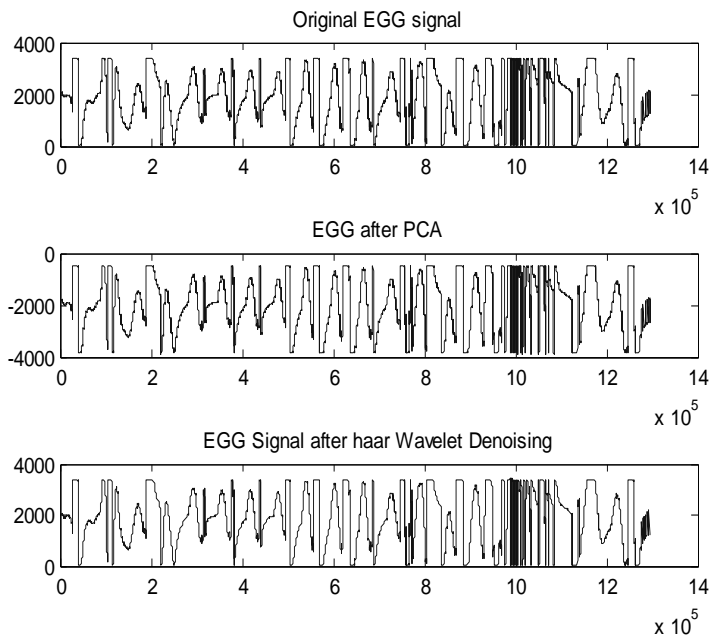

Figure 3. Denoising of EGG signal with Haar wavelet transforms
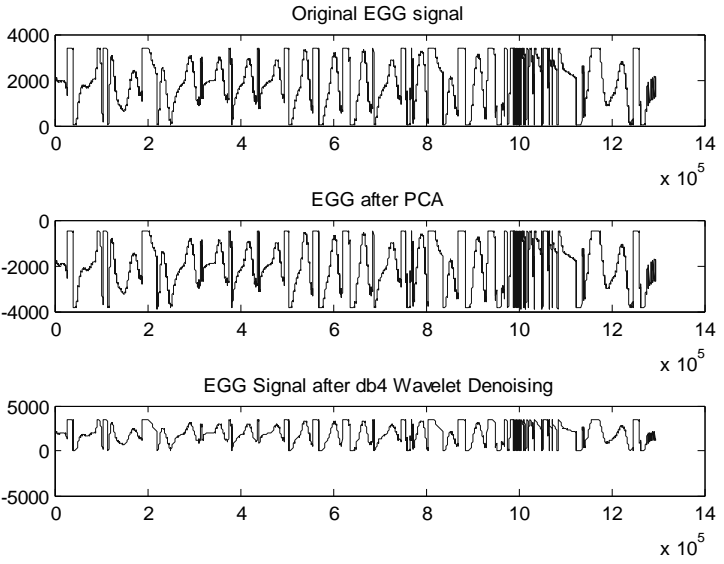

Figure 4. Denoising of EGG signal with db4 wavelet transforms

\section{RESULTS AND DISCUSSION}

Wavelet transform is used to denoise the EGG signal, which increases the reduction of noises from EGG signal, which may be under or above EGG frequency limit. From the database the data analyzed for detecting frequency and power of the EGG signal of the normal subjects and the patients with digestive system disorders after wavelet denoising using Welch power spectral Density Estimation as shown in Figuer.5, which shows the range of frequencies and power for the dyspepsia patient with frequency $0.02344 \mathrm{~Hz}$ and power $48.42 \mathrm{db}$ in postprandial condition. In this study, we have used the EGG setup to record myoelectrical activity for the patients suffering from Dyspepsia, Stomach ulcer, tachygastria, bradygastria and normal subjects for both preprandial and postprandial condition [9, 11]. Figure 6 shows approximation coefficient plot of EGG for person with Tachygastria is obtained with DWT and Figure 7 shows the plot reconstructed EGG signal for person with Tachygastria with large number of peaks where as normal subjects 5 peaks and bradygastria with less number of peaks.

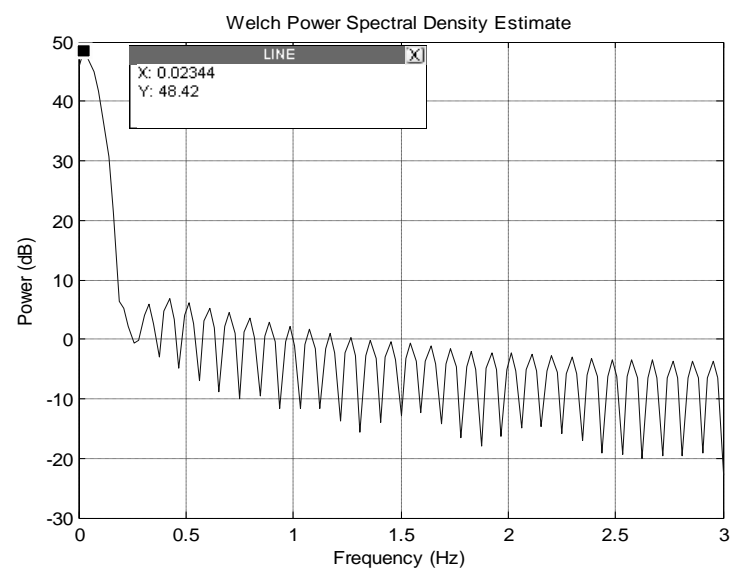

Figure 5. Welch power spectral Density Estimation for disorder subjects
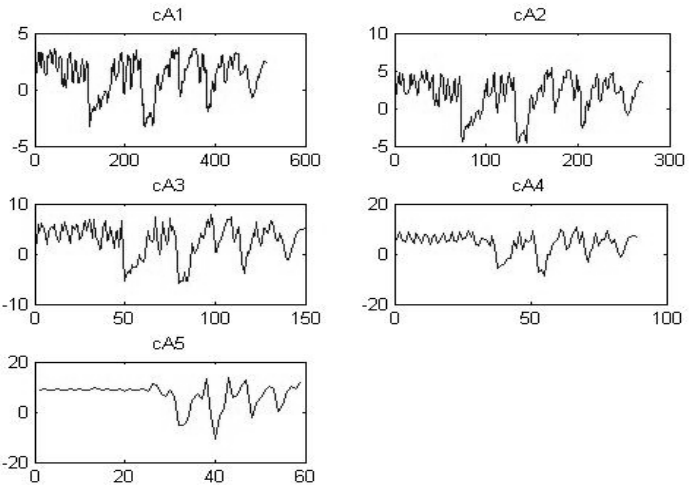

Figure 6. Approximation coefficient plot of EGG for person with Tachygastria
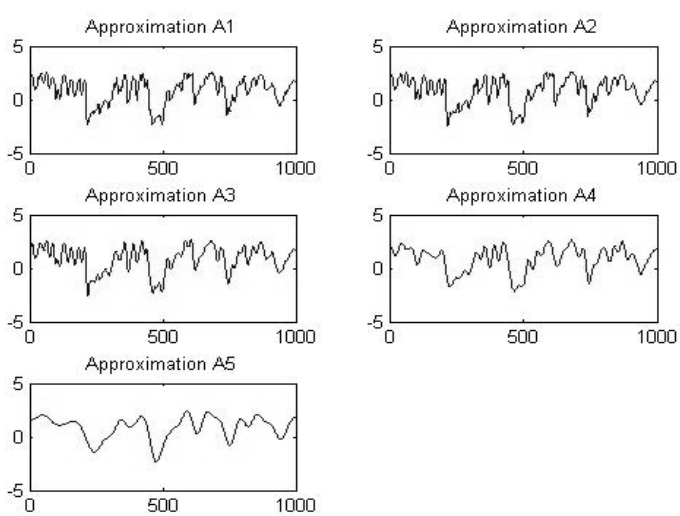

Figure 7. Reconstructed EGG signal for person with Tachygastria 


\section{CONCLUSION}

In this paper, the acquisition of the EGG [12,13] from normal subjects and abnormal subjects who are suffering from different stomach disorders is succeeded at the fair amount of accuracy. The study is conducted in reputed hospital using active electrode and formed a database for EGG signals under the monitor and guidance of the gastroenterologist the signal analysis is performed using MATLAB software in reconstructing, denoising, power and frequency calculation of the EGG signal from the database. The power and frequency of the EGG are compared and it is observed that when the power of the signal increased corresponding frequency is decreased for digestive disorder patient when compare to normal subjects. This fact may very much support the previous research work done in the field. The future work in this project would be to acquire EGG from patients suffering from different diseases to form a strong database. The signal analysis can be extended further as challenge to the rese archer to find best analysis techniques which should detect a minute changes in the frequency in the spectral analysis to a greater extent. The EGG signals which may help to diagnose the digestive disorders more efficiently and precisely.

\section{ACKNOWLEDGMENTS}

The authors acknowledge their indebtedness to the following medical experts Dr L Venkatakrishnan, M.D., D.M.,D.N.B., Head of Gastroenterology Dept., Dr.J.Krishnaveni, M.D.,D.N.B., Gastroenterologist from PSG Hospitals, Coimbatore, Dr.T.S.ChandraSekar,M.D, M.D.,D.M, Interventional Gastroenterologist from Medindia Hospital,Coimbatore for their support and for permitting us to use the facilities at the hospitals for live testing of the recording setup and sharing valuable patient database with us. We are also acknowledging the Management, Principal, Director, Head of the BME/EIE of Sri Ramakrishna Engineering College, Coimbatore for their support in acquiring data from the different patients at the department of biomedical Engineering

\section{REFERENCES}

[1] W.C.Alvarez. , 1922. The Electrogastrogram and what it shows. JAMA, vol 78,1116-1118.

[2] A.J.P.M. Smout, E.J. Van Der Schee, J.L.Grashuis, 1980. What is measured in electrogastrography?" Digestive Diseases and Sciences, 253.

[3] C.F Code and J.A Marlett,1974. Modern Medical Physiology: Canine Tachygastria, Mayo clinic proceeding, vol.49, 325-332.

[4] R.L.Telander et al, ,1978. Human gastric agony with tachygastria and gastric retention", Gastroenterology. vol.75,495-501.
[5] T.L.Abell, J.R.Malagelada, 1988.Electrogastrography: Current assessment and future perspectives. Digestive Diseases and Sciences, vol 33,982-992.

[6] J. Chen, R.W. McCallum, 1991.Electrogastrography: measurement, analysis and prospective applications. Medical \&Biological Engineering \& Computing, vol 29, 339-350.

[7] G.Riezzo, F.Pezzolla, J. Thouvenot , et al, 1992. Reproducibility of cutaneous recordings of electrogasography in the fasting state in man, Pathology Biology, vol 40,889-894.

[8] M.P. Mintchev, Y.J. Kingma, K.L. Bowes, 1993.Accuracy of cutaneous recordings of gastric electrical activity. Gastroenterology, vol 104, 1273-1280.

[9] B.Pfaffenban, R.J.Adamek, K.kuhn, et.al. , 1995. Electrogastrogra-phy in healthy subjects. Evalation of normal values influences of age and gender. Digestive Diseases and Sciences, vol 40,445-450.

[10] J.D.Z.Chen,Z.Lin, I.Pan, et al. 1996.Abnormal gastric myoelectrical activity and delayed gastric emptying in patients with symptoms suggestive of gastro paresis. Digestive Diseases and Sciences, vol 41,1538-1545.

[11] J D Z Chen, 1998. Noninvasive Measurement of gastric Myoelectrical Activity and its Analysis and Applications, Annual International Conference of the IEEE Engineering in Medicine and Biology Society, Vol.20(6),2802-2807.

[12] A.Leahy, K.Besherdas, C.Clayman, I.Mason, O.Epstein. , 1999.Abnormalities of the electrogastrogram in functional dyspepsia. American Journal of Gastroenterology, vol 94(4), 1023-1028.

[13] Han-Chang Wu,Kuang-Ching,et al, , 1998. Power distribution analysis of cutaneous Electrogastrography using discrete wavelet transform, International Conference of the IEEE engineering in medicine and biology society, Vol.20(6), 3227-3229.

[14] DZ Chen, Zhiyue Lin , 2006. ElectrogastrogramEncyclopedia of Medical Devices and Instrumentation", Second Edition, edited by John G. Webster, John Wiley \& Sons, Inc.

[15] G.Gopu, R.Neelaveni, K.Porkumaran, 2008. "Investigation of Digestive System Disorders using Electrogastrogram" In Proceedings of the international conference on Computer and Communication Engineering.

[16] K.P.Soman, K.I. Ramachandran, ,2004.Insight to wavelets from Theory to Practice",Prentice Hall of India Pvt.Ltd,New delhi. 